\title{
MATHEMATICAL AND NUMERICAL BASIS OF BINARY ALLOY SOLIDIFICATION MODELS WITH SUBSTITUTE THERMAL CAPACITY. PART II
}

\author{
Ewa Wegrzyn-Skrzypczak ${ }^{1}$, Tomasz Skrzypczak ${ }^{2}$ \\ ${ }^{I}$ Institute of Mathematics, Czestochowa University of Technology \\ Czestochowa, Poland \\ ${ }^{2}$ Institute of Mechanics and Machine Design, Czestochowa University of Technology \\ Czestochowa, Poland \\ Iewa.skrzypczak@im.pcz.pl, ${ }^{2}$ skrzyp@imipkm.pcz.pl
}

\begin{abstract}
In this paper, the results obtained from five models of the solidification with substitute thermal capacity were compared. The calculations were carried out for steel containing $0.35 \%$ carbon with using an in-home solver based on the finite element method (FEM). A comparison was made on the base of analysis of the cooling curves at selected nodes.
\end{abstract}

Keywords: solidification, binary alloy, substitute thermal capacity, numerical calculations

\section{Introduction}

The main assumptions of the mathematical and numerical models used in the presented paper were discussed in detail in [1]. Numerical modeling of solidification can be divided into solidification at a constant temperature, for example in case of pure metals $[2,3]$ or solidification in the range of temperatures. Solidification of the binary alloy occurs in a range of $\left[T_{S}, T_{L}\right]$ temperatures specifying the beginning and the end of the process. Inside the area limited by liquidus $\left(T_{L}\right)$ and solidus $\left(T_{S}\right)$ the emission of heat is observed. In the case of steel, for the simplicity of numerical implementation, models with so-called substitute thermal capacity are widely used [4-7]. An introduction to the model with substitute thermal capacity comes down to a suitable modification of the function describing increase in thermal capacity in the mushy zone [1]. In this case, regardless of the adopted function, the integration procedure within the limits of $\left[T_{S}, T_{L}\right]$ should lead to the same value of total thermal capacity. However, the results of numerical models can be different due to the adopted quality of the spatial discretization, time step, etc. Using an in-home solver based on the finite element method the results obtained from implemented numerical models of the solidification with substitute thermal capacity were compared. 


\section{Mathematical and numerical descriptions}

The basis of the mathematical model is an equation of energy [1]:

$$
\frac{\partial}{\partial x}\left(\lambda_{m} \frac{\partial T}{\partial x}\right)+\frac{\partial}{\partial y}\left(\lambda_{m} \frac{\partial T}{\partial y}\right)=\rho_{m} c_{e f f} \frac{\partial T}{\partial t}
$$

where $T[\mathrm{~K}]$ denotes temperature, $c_{\text {eff }}[\mathrm{J} /(\mathrm{kgK})]$ is substitute heat capacity, $\rho_{m}$ $\left[\mathrm{kg} / \mathrm{m}^{3}\right]$ - averaged density, $\lambda_{m}[\mathrm{~W} /(\mathrm{mK})]$ - averaged coefficient of thermal conductivity, $t[\mathrm{~s}]$ - time.

Equation (1) is supplemented by the boundary conditions of the first and second kind and appropriate initial condition:

$$
\begin{gathered}
\Gamma_{1}: T=T_{b} \\
\Gamma_{2}:-\lambda \frac{\partial T}{\partial n}=-\lambda \nabla T \cdot \mathbf{n}=q_{b} \\
T(t=0)=T_{0}
\end{gathered}
$$

where $T_{b}[\mathrm{~K}]$ is temperature on the boundary, $q_{b}\left[\mathrm{~W} / \mathrm{m}^{2}\right]-$ known heat flux, $\partial T / \partial n$ - directional derivative of temperature, $\mathbf{n}$ - vector normal to the boundary $\Gamma_{2}, T_{0}[\mathrm{~K}]$ - initial temperature.

Substitute thermal capacity is determined using the following hypotheses:

Hypothesis $1[4]$ :

$$
c_{\text {eff }}(T)=c_{m}+\frac{L}{T_{L}-T_{S}}
$$

Hypothesis 2 [4]:

$$
c_{\text {eff }}(T)=c_{s}+\left(c_{\max }-c_{s}\right) \frac{T-T_{S}}{T_{L}-T_{S}}
$$

where $c_{\max }$ is determined from the following equation [4]:

$$
\frac{1}{2}\left(T_{L}-T_{S}\right)\left(c_{\max }+c_{S}\right)=c_{m}\left(T_{L}-T_{S}\right)+L
$$

Hypothesis 3 [4]:

$$
c_{e f f}(T)=c_{s}+(p+1)\left(c_{m}+\frac{L}{T_{L}-T_{S}}-c_{s}\right)\left(\frac{T-T_{S}}{T_{L}-T_{S}}\right)^{p}
$$


Hypothesis 4 - Borisow model [4, 7]:

$$
c_{e f f}(T)=c_{m}+\frac{L}{(1-k)\left(T_{p}-T_{L}\right)}\left(\frac{T_{p}-T_{L}}{T_{p}-T}\right)^{\frac{2-k}{1-k}}
$$

Hypothesis 5 - Samojłowicz model $[3,6]$ :

$$
c_{\text {eff }}(T)=c_{m}-m_{L} m_{S} \frac{L\left(T_{S}-T_{L}\right)}{\left[m_{L}\left(T-T_{L}\right)-m_{S}\left(T-T_{S}\right)\right]^{2}}
$$

where $c_{m}, c_{s}[\mathrm{~J} /(\mathrm{kgK})]$ are average specific heat and specific heat in solid phase respectively, $L[\mathrm{~J} / \mathrm{kg}]$ - latent heat of solidification, $k$ - phase separation coefficient, $T_{p}[\mathrm{~K}]$ - temperature of melting of pure iron, $m_{L}$ - tangent of the slope of the liquidus line, $m_{S}$ - tangent of the slope of the solidus line.

Using the procedures of spatial and implicit time discretization [8] with respect to equation (1) leads to the global FEM equation [1]:

$$
\left(\mathbf{K}+\frac{1}{\Delta t} \mathbf{M}\right) \mathbf{T}^{f+1}=\mathbf{B}+\frac{1}{\Delta t} \mathbf{M} \mathbf{T}^{f}, \Delta t=t^{f+1}-t^{f}
$$

where $\mathbf{K}$ denotes the heat conductivity matrix, $\mathbf{M}$ - heat capacity matrix, $\mathbf{B}$ - righthand side vector, $\Delta t[\mathrm{~s}]$ - time step, $f$ - time level.

\section{Examples of calculation}

Computer simulations of the solidification were made assuming the material properties of steel containing $0.35 \%$ carbon (Tab. 1). The calculations were carried out in the rectangular area of dimensions $200 \times 50 \mathrm{~mm}$ (Fig. 1).

$$
q_{b}=0\left[\frac{W}{m^{2}}\right]
$$

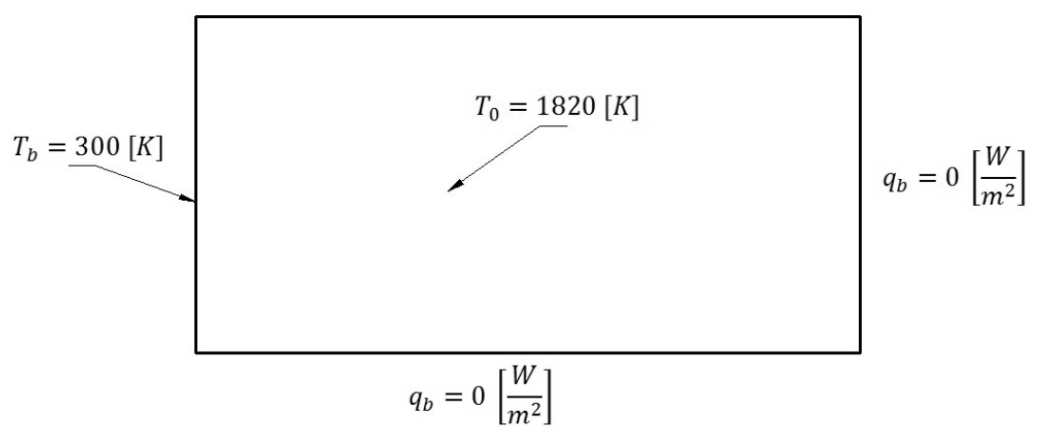

Fig. 1. Boundary and initial conditions 
They were made in five series each time changing the way of mathematical description of substitute thermal capacity. Boundary and initial conditions are presented in Figure 1. Such a choice of boundary conditions has made facilitate comparison of position of the solidus and liquidus isotherms at selected moments of time for subsequent distribution hypotheses of $c_{\text {eff. }}$. The time step and the material properties were constant.

Table 1

Alloy material properties [4] and parameters used in the calculations

\begin{tabular}{|c|c|c|}
\hline Parameter & Solid phase & Liquid phase \\
\hline$c[\mathrm{~J} /(\mathrm{kgK})]$ & 690 & 820 \\
\hline$\rho\left[\mathrm{kg} / \mathrm{m}^{3}\right]$ & 7500 & 7200 \\
\hline$\lambda[\mathrm{W} /(\mathrm{mK})]$ & 35 & 20 \\
\hline$T_{S}, T_{L}[\mathrm{~K}]$ & \multicolumn{2}{|c|}{1743,1778} \\
\hline$L[\mathrm{~J} / \mathrm{kg}]$ & $2.7 \cdot 10^{5}$ \\
\hline$p$ & \multicolumn{3}{|c|}{6} \\
\hline$T_{p}[\mathrm{~K}]$ & \multicolumn{3}{|c|}{0.411} \\
\hline$k$ & \multicolumn{3}{|c|}{$-94.826,-194.826$} \\
\hline$m_{L}, m_{S}$ &
\end{tabular}

In Table 2 the position of the solidus-liquidus isotherms in selected moments for five solidification hypothesis are collected. As a result of the introduction of appropriate boundary condition on the left wall of the tested area and the thermal insulation on the other walls, solid phase grows in a horizontal direction from left to right side, with the result that $T_{S}$ and $T_{L}$ isotherms are arranged vertically, parallel to each other. This allows easy and precise determination of their temporary positions on the horizontal axis.

Table 2

Comparison of the temporary positions of the isotherms $T_{S}$ and $T_{L}$

\begin{tabular}{|c|c|c|c|c|c|c|}
\hline \multirow{4}{*}{} & \multicolumn{9}{|c|}{ Time } & \multicolumn{2}{c|}{$750 \mathrm{~s}$} \\
\cline { 2 - 7 } & \multicolumn{2}{|c|}{$250 \mathrm{~s}$} & \multicolumn{2}{c|}{$500 \mathrm{~s}$} \\
\cline { 2 - 7 } & $\begin{array}{c}\text { position } \\
\text { of isotherm } \\
\left(T_{S}\right) \\
{[\mathrm{mm}]}\end{array}$ & $\begin{array}{c}\text { position } \\
\text { of isotherm } \\
\left(T_{L}\right) \\
{[\mathrm{mm}]}\end{array}$ & $\begin{array}{c}\text { position } \\
\text { of isotherm } \\
\left(T_{S}\right) \\
{[\mathrm{mm}]}\end{array}$ & $\begin{array}{c}\text { position } \\
\text { of isotherm } \\
\left(T_{L}\right) \\
{[\mathrm{mm}]}\end{array}$ & $\begin{array}{c}\text { position } \\
\text { of isotherm } \\
\left(T_{S}\right) \\
{[\mathrm{mm}]}\end{array}$ & $\begin{array}{c}\text { position } \\
\text { of isotherm } \\
\left(T_{L}\right) \\
{[\mathrm{mm}]}\end{array}$ \\
\hline 1 & 82 & 89 & 116 & 124 & 142 & 152 \\
\hline 2 & 83 & 88 & 117 & 123 & 143 & 151 \\
\hline 3 & 83 & 87 & 117 & 123 & 142 & 149 \\
\hline 4 & 85 & 90 & 120 & 126 & 146 & 154 \\
\hline 5 & 83 & 90 & 116 & 126 & 142 & 154 \\
\hline
\end{tabular}


Temporary positions of the solidus and liquidus isotherms are similar. This is due to the fact that the average specific heat in the solid-liquid area in each case has a similar value, which implies a comparable rate of solidification.

For a more comprehensive analysis of the results a comparison of cooling curves at selected nodes in the test area was made. In Table 3 coordinates of the selected nodes are collected, while in Figures 2-4 a comparison of the cooling curves is presented.

Table 3

Coordinates of selected nodes

\begin{tabular}{|c|c|c|}
\hline \multirow{2}{*}{ Index of node } & \multicolumn{2}{|c|}{ Coordinates } \\
\cline { 2 - 3 } & $\mathrm{x}[\mathrm{mm}]$ & $\mathrm{y}[\mathrm{mm}]$ \\
\hline 297 & 50 & 50 \\
\hline 5078 & 100 & 50 \\
\hline 5573 & 150 & 50 \\
\hline
\end{tabular}

The graphs of cooling curves in selected nodes (Figs. 2-4) clearly show good agreement between compared hypotheses of distribution $c_{\text {eff. }}$.

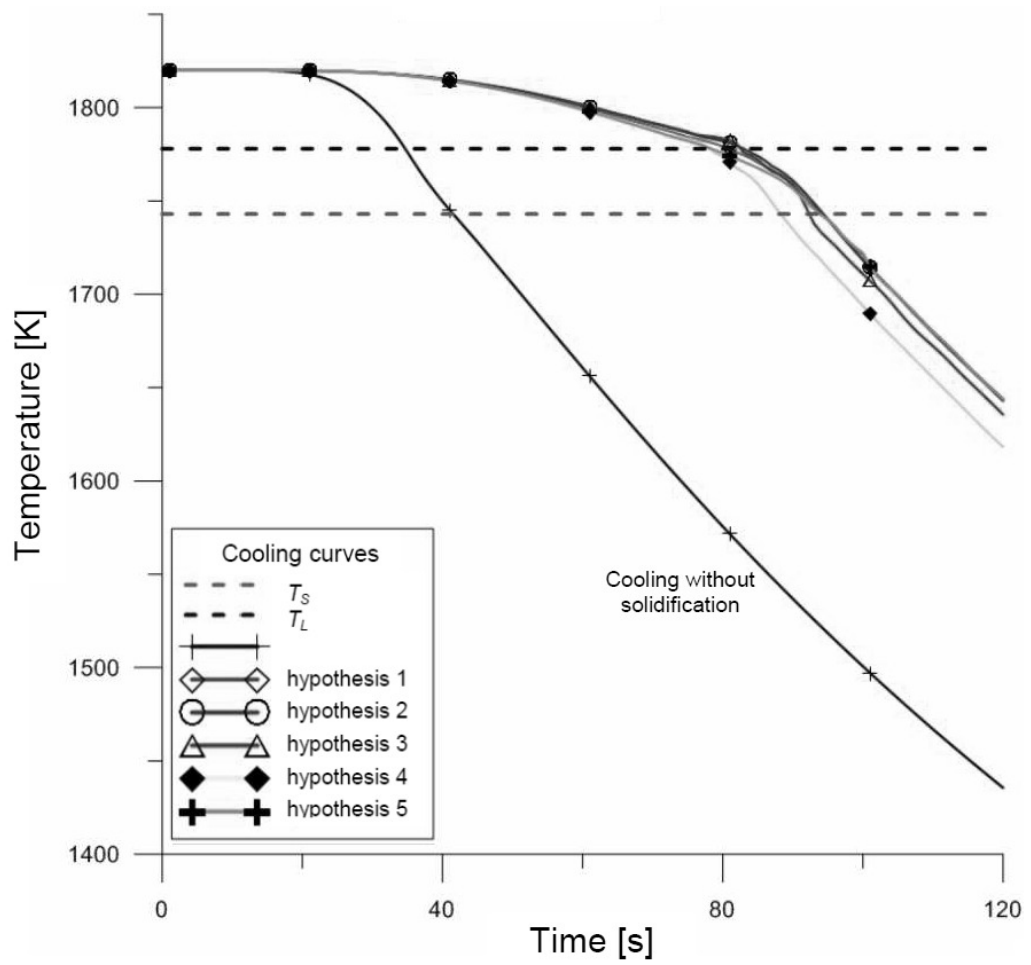

Fig. 2. Cooling curves for node $297(x=50 \mathrm{~mm})$ 


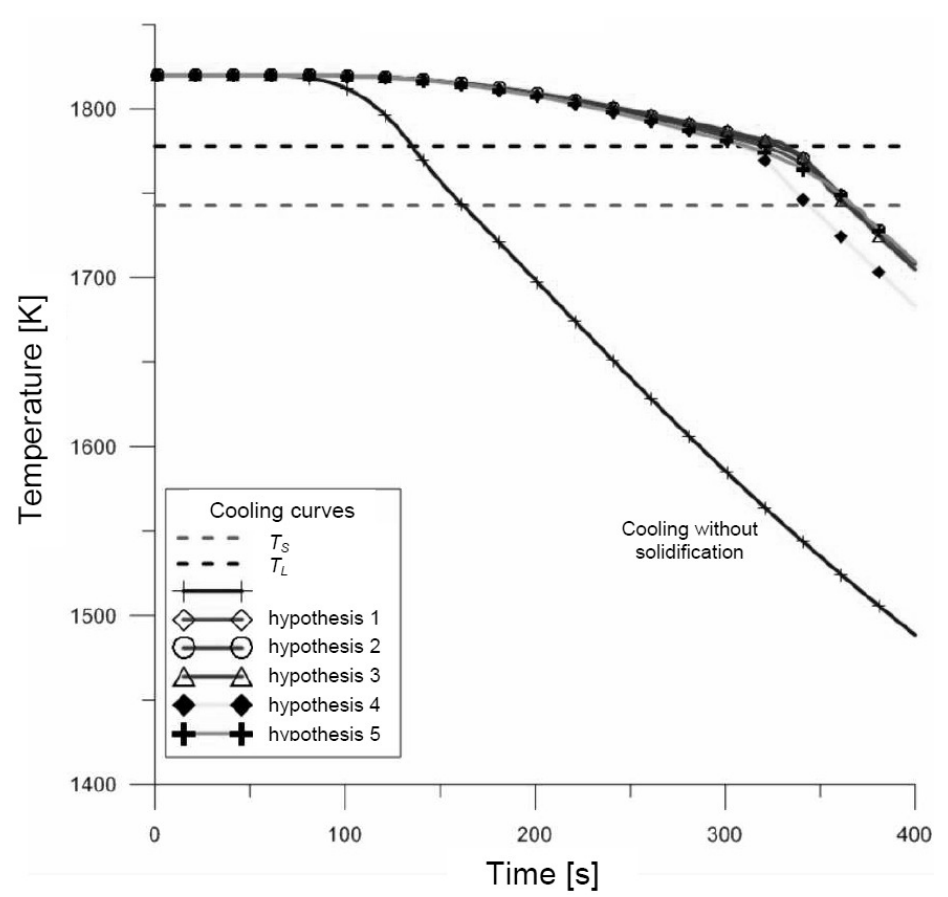

Fig. 3. Cooling curves for node $5078(x=100 \mathrm{~mm})$

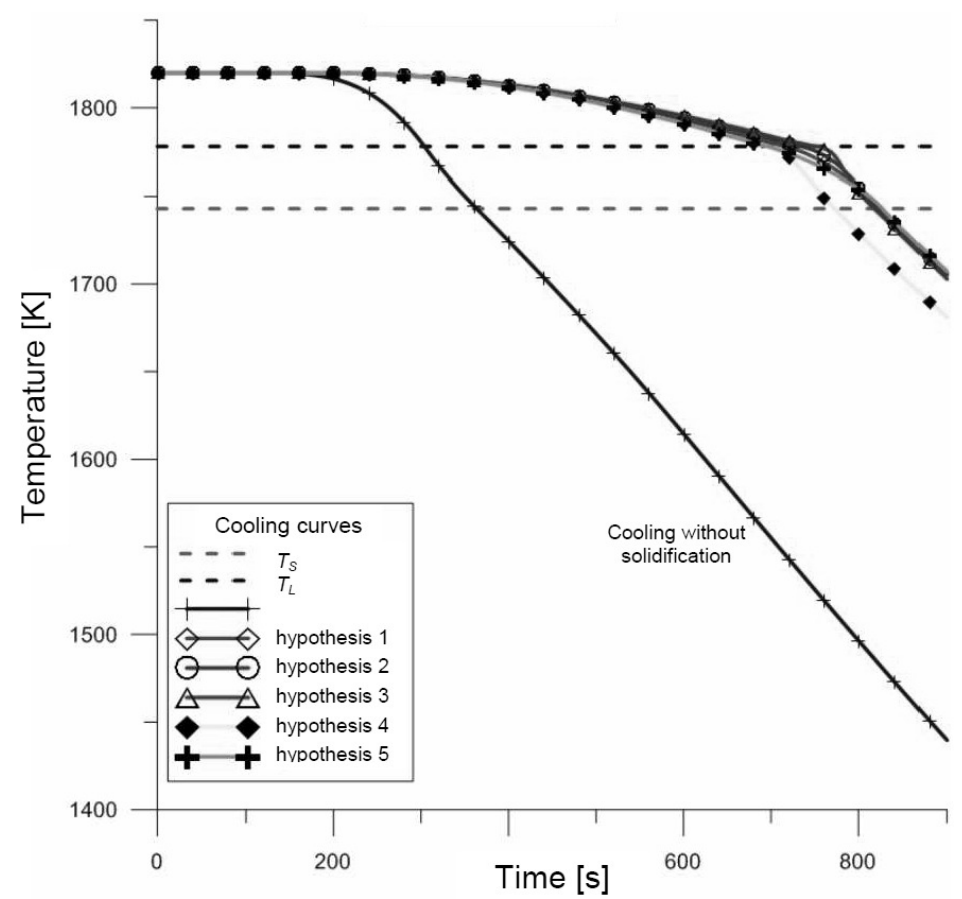

Fig. 4. Cooling curves for node $5573(x=150 \mathrm{~mm})$ 


\section{Conclusions}

Tested models of solidification with substitute thermal capacity give comparable results. Each of the compared hypotheses can be used for modeling solidification of steel. In the case of other alloys such as bronze, brass or aluminum alloys the agreement between the discussed models may be less [4]. In-home computer program, thanks to its flexibility, allows easy modification of solvers and relatively comfortable adaptation to solve three-dimensional problems.

\section{References}

[1] Węgrzyn-Skrzypczak E., Skrzypczak T., Mathematical and numerical basis of binary alloy solidification models with substitute thermal capacity. Part I, Journal of Applied Mathematics and Computational Mechanics 2014, 13(2), 127-132.

[2] Skrzypczak T., Węgrzyn-Skrzypczak E., Mathematical and numerical model of solidification process of pure metals, International Journal of Heat and Mass Transfer 2012, 55(15-16), 4276-4284 .

[3] Skrzypczak T., Sharp interface numerical modeling of solidification process of pure metal, |Archives of Metallurgy and Materials 2012, 57(4), 1189-1199.

[4] Mochnacki B., Suchy J.S., Modelowanie i symulacja krzepnięcia odlewów, Wydawnictwo Naukowe PWN, Warszawa 1993.

[5] Siedlecki J., Tuzikiewicz W., Substitute thermal capacity of binary alloys. Review of hypotheses, Scientific Research of the Institute of Mathematics and Computer Science 2012, 4, 11, 121-129.

[6] Majchrzak E., Mochnacki B., Suchy J.S., Identification of substitute thermal capacity of solidifying alloy, Journal of Theoretical and Applied Mechanics 2008, 46, 2, 257-268.

[7] Mochnacki B., Modele matematyczne kierunkowej krystalizacji stopów, Krzepnięcie Metali i Stopów 1984, 7, 125-145.

[8] Grandin H., Fundamentals of the Finite Element Method, Waveland Press, Paris 1991. 